\title{
Correlation between dermoscopic and histopathological diagnoses of atypical nevi in a dermatology outpatient clinic of the Medical School of São José do Rio Preto, SP, Brazil ${ }^{*}$
}

\author{
Correlação entre os diagnósticos dermatoscópico e histopatológico de nevos \\ atípicos no ambulatório de dermatologia da Faculdade de Medicina de São José \\ do Rio Preto, SP, Brasil
}

\author{
João Roberto Antonio ${ }^{1}$ \\ Solange Corrêa Garcia Pires D'Avila \\ Lívia Arroyo Trídico ${ }^{5}$
}

\author{
Rosa Maria Cordeiro Soubhia ${ }^{2}$ \\ Adriana Cristina Caldas ${ }^{4}$ \\ Fernanda Tomé Alves ${ }^{5}$
}

\begin{abstract}
BACKGROUND: The incidence of cutaneous melanoma is increasing worldwide. Since it is an aggressive neoplasm, it is difficult to treat in advanced stages; early diagnosis is important to heal the patient. Melanocytic nevi are benign pigmented skin lesions while atypical nevi are associated with the risk of developing melanoma because they have a different histological pattern than common nevi. Thus, the clinical diagnosis of pigmented lesions is of great importance to differentiate benign, atypical and malignant lesions. Dermoscopy appeared as an auxiliary test in vivo, playing an important role in the diagnosis of pigmented lesions, because it allows the visualization of structures located below the stratum corneum. It shows a new morphological dimension of these lesions to the dermatologist and allows greater diagnostic accuracy. However, histopathology is considered the gold standard for the diagnosis.

OвJестіVE: To establish the sensitivity and specificity of dermoscopy in the diagnosis of pigmented lesions suspected of malignancy (atypical nevi), comparing both the dermatoscopic with the histopathological diagnosis, at the Dermatology Service of the outpatient clinic of Hospital de Base, São José do Rio Preto, SP.

MetHods: Analysis of melanocytic nevi by dermoscopy and subsequent biopsy on suspicion of atypia or if the patient so desires, for subsequent histopathological diagnosis.

RESULTS: Sensitivity: $93 \%$. Specificity: $42 \%$.

CONCLUSIONS: Dermoscopy is a highly sensitive method for the diagnosis of atypical melanocytic nevi. Despite the low specificity with many false positive diagnoses, the method is effective for scanning lesions with suspected features of malignancy.

Keywords: Dermoscopy; Diagnosis; Nevus, pigmented

Resumo: FundAMENTOS: A incidência do melanoma cutâneo tem aumentado mundialmente e, por ser uma neoplasia agressiva de difícil tratamento em estágios avançados, o diagnóstico precoce é fundamental para cura do paciente. Os nevos melanocíticos são lesões pigmentadas benignas da pele, enquanto os nevos atípicos, por possuírem padrão histológico diferente dos nevos comuns, estão associados ao risco de desenvolvimento de melanoma cutâneo. Dessa forma, o diagnóstico clínico das lesões pigmentadas é de grande importância para diferenciar lesões benignas, atípicas e malignas. A dermatoscopia surgiu como um exame auxiliar in vivo, com papel fundamental no diagnóstico de lesões pigmentadas. Como permite a visualização das estruturas localizadas abaixo do estrato córneo, traz uma nova dimensão morfológica dessas lesões para o dermatologista, permitindo maior precisão diagnóstica, porém, o diagnóstico padrão ouro é a histopatologia. OвJETIVOS: Estabelecer a sensibilidade e especificidade da dermatoscopia no Serviço de Dermatologia do Ambulatório do Hospital de Base da cidade de São José do Rio Preto, SP, no diagnóstico de lesões pigmentadas com suspeita de malignidade (nevos atípicos), comparando o diagnóstico dermatoscópico ao histopatológico. MÉTODOs: Análise de nevos melanocíticos por dermatoscopia e conseqüente biópsia em caso de suspeita de atipia, ou caso o paciente desejar, para realizar posterior diagnóstico histopatológico. Resultados: Sensibilidade: 93\%. Especificidade: 42\%. CONCLUSÕES: A dermatoscopia é um método altamente sensível para o diagnóstico de nevos melanocíticos atípicos. Apesar da baixa especificidade, apresentando grande quantidade de diagnósticos falsos positivos, o método é eficaz no objetivo de rastrear lesões com características suspeitas de malignidade.
\end{abstract}

Palavras-chave: Dermoscopia; Diagnóstico; Nevo pigmentado

\section{Received on 21.01.2012}

Approved by the Advisory Board and accepted for publication on 17.06.2012.

Work carried out at the Dermatology Outpatient Clinic of the Medical School (Faculdade de Medicina) of São José do Rio Preto - FAMERP - São José do Rio Preto (SP), Brazil.

Financial Support: None.

Conflict of Interest: None.

Doctorate in Health Science from Faculdade de Medicina de São José do Rio Preto (FAMERP) - Emeritus Professor and Head of Dermatology of Faculdade de Medicina de São José do Rio Preto (FAMERP) and Dermatological Service of Hospital de Base, Faculdade de Medicina de São José do Rio Preto (FAMERP) São José do Rio Preto (SP), Brazil.

Doctorate in Health Science from Faculdade de Medicina de São José do Rio Preto(FAMERP) - Adjunct Professor of the Dermatology Subjec of Faculdade de Medicina de São José do Rio Preto (FAMERP) - São José do Rio Preto (SP), Brazil.

Doctorade in Pathology from Faculdade de Medicina da Universidade de São Paulo (FMUSP) - Adjunct Professor of the Anatomical Pathology Subject of Faculdade de Medicina de São José do Rio Preto (FAMERP) - São José do Rio Preto (SP), Brazil.

MD, Dermatologist from the Medical School of São José do Rio Preto (FAMERP) - Collaborator of the Dermatology Department of Hospital de Base, Faculdade de Medicina de São José do Rio Preto (FAMERP) - São José do Rio Preto (SP), Brazil.

Undergraduated Medicine Student - Faculdade de Medicina de São José do Rio Preto (FAMERP) - São José do Rio Preto (SP), Brazil. 


\section{INTRODUCTION}

Cutaneous melanoma is a more aggressive and dangerous form of skin cancer. ${ }^{1}$ Its incidence has increased in recent decades worldwide, becoming one of the most common cancers in white populations, especially in young people. There is evidence of growing incidence over the past 50 years, related to increased exposure to sunlight. ${ }^{2-4}$ It is a form of cancer with high metastatic potential. ${ }^{5}$ Due to the severity of cutaneous melanoma, the medical / scientific community has mobilized to advise on the importance of early treatment. ${ }^{4,6}$ The curability of melanoma by surgical excision is well established when in the early stages, thus early diagnosis is important. ${ }^{7}$

Melanocytic nevi are benign pigmented lesions composed of melanocyte clusters located in the epidermis (junctional nevus), dermis (intradermal nevi) or both areas (compound nevi). Atypical nevus, a distinct entity, is characterized by pigmented lesions acquired with clinical and histological standards different from common nevi. ${ }^{8}$

Several epidemiological studies have shown that the risk for developing melanoma is statistically significant with the presence of atypical nevi. ${ }^{9-11}$ It is believed that atypical nevi are precursor lesions of cutaneous melanoma. ${ }^{12}$ According to Elder et al., 1980, melanomas can occur associated with pre-existing atypical nevi, and there was clinical evidence of this finding in at least 2 / 3 of patients, and remaining nevi in at least $50 \%$ of the primary lesions. ${ }^{13}$

Given the importance of atypical nevi as a risk factor for melanoma, accurate diagnosis has become a major challenge. The ultimate goal of treating a patient with atypical nevi is the prevention of melanoma, which means modification of risk factors, when possible, and patient monitoring so that early melanomas can be removed in a curable stage. ${ }^{14}$

As pigmented skin lesions are not often diagnosed by their clinical features, additional criteria are required for a clinical diagnosis of greater accuracy. Dermoscopy can be considered an auxiliary diagnosis method, also known as surface microscopy or epiluminescence microscopy. ${ }^{15-17}$

The introduction of dermoscopy in clinical practice of dermatology has brought a new morphological dimension when facing pigmented skin lesions. It is a simple, practical, non-invasive, financially feasible technique which allows the visualization of patterns and morphological features that could not be observed with the naked eye. This "submicroscopic" observation of pigmented lesions does not replace the clinical diagnosis, but it can complement a new morphological criteria approach that helps to differentiate melanocytic from non-melanocytic lesions, and especially to diagnose melanoma. ${ }^{18}$
We should consider dermoscopy an intermediate method between clinical diagnosis and histopathological study of the lesion, since the latter remains the gold standard for the diagnosis of melanoma, which can be useful to provide staging, treatment and prognosis. ${ }^{19,20}$

It has just been shown that dermoscopy improves the sensitivity and specificity of melanoma diagnosis by $35 \%$, compared to clinical diagnosis. ${ }^{21-23}$ Studies conducted by the medical school of Vienna, Austria have confirmed the efficacy of dermoscopy, showing a representative increase in the correct classification of pigmented lesions, mainly by non-expert dermatologists. ${ }^{24}$

On the other hand, Procianoy, 2009, concluded in his work that dermoscopy is not a suitable method for the diagnosis of atypical nevi. ${ }^{25}$ Other studies call into question certain aspects of dermoscopy, especially when practiced by inexperienced people and conclude that it may even compromise the diagnostic accuracy. ${ }^{26}$

Steiner, Pehambereger and Wolf, 1993 argued that the use of dermoscopy increases the diagnostic accuracy of clinically equivocal melanocytic lesions, especially early melanoma and atypical nevi, and allows the distinction between benign and malignant patterns of growth. ${ }^{6,27}$ Salopek et al, 2001, found that the sensitivity of dermoscopy varies between 62 and $94 \%{ }^{28}$

We can observe that the dermatoscopic method has been widely used nowadays, especially given the need for early diagnosis of pigmented skin lesions. Therefore, to assess the method according to its sensitivity and specificity is extremely important for those who use it.

In addition, the evaluation of dermoscopy as a diagnostic method in the city of São Jose do Rio Preto is fundamental, since the city is located at $20^{\circ} 49^{\prime} 11^{\prime \prime}$ $S$ latitude. It has a tropical climate, average yearly temperature of $23^{\circ} \mathrm{C}$, receiving high incidence of ultraviolet rays, which constitutes an important risk factor for the development of malignant pigmented lesions for the population of that city.

Facing different conclusions about the use of dermoscopy in previous studies, and because of the importance of evaluating this method, this study aims to analyze the sensitivity and specificity of the dermatoscopic diagnosis of atypical nevi, comparing it with histopathology (gold standard) in patients from the outpatient clinic of Dermatology Service of the Medical School of São José do Rio Preto.

\section{PATIENTS AND METHODS}

In this cross-sectional observational study, nevic lesions of patients attended at the Dermatology Service of São José do Rio Preto from August 2010 to 
May 2011 (10 months) were analyzed. This study considered nevoid lesions of patients who had clinical suspicion of atypia or who desired their surgical removal and characterized the study population.

During this period, all lesions of all patients with these characteristics who came to the Dermatology Service of São José do Rio Preto were part of the sample selection. Thus, the present study analyzed nevoid lesions in 48 selected patients, 37 women and 11 men aged between 14 and 72 years to evaluate the sensibility and specificity of the dermatoscopic method for diagnosis of pigmented lesions. A total of 106 lesions were analyzed by dermoscopy and histopathology after surgical removal. All the patients included signed a consent form, and this study was approved by the Research Ethics Committee of the Medical School of São José do Rio Preto

According to clinical analysis, the lesions were considered atypical in cases of a macular component in at least one area of the lesion associated with at least three of the following features: irregular and not well defined borders; size equal to or greater than $5 \mathrm{~mm}$, several colors and presence of erythema.

Lesions suspected to be atypical were analyzed by dermoscopy through Pattern Analysis Methodology, which analyzes global pattern (reticular, globular, cobblestone, pointillist, homogeneous, parallel, starburst, multicomponent, nonspecific and vascular) and local pattern, providing relatively reliable markers for the diagnosis of benign and malignant lesions. This method criteria were established by histopathological analysis of lesions and correlation with dermoscopy., ${ }^{6,29}$

After performing dermoscopy, melanocytic lesions with clinical diagnosis of melanocytic atypia, and those patients who desired to remove these lesions were subjected to histopathological diagnosis, performed in the Pathology and Forensic Medicine Department of the Medical School of São José do Rio Preto. Dermoscopy was considered positive when the diagnosis was atypical nevus or cutaneous melanoma. The other dermatoscopic diagnoses were considered negative results. The occurrence of false positive and false negative results was observed by histopathological exam, considered the gold standard.

Thus, through the correlation between dermatoscopic and histopathological diagnoses of the pigmented lesions, the sensitivity and specificity of dermoscopy in the atypical nevi diagnosis at the Dermatology Service of the Medical School of São José do Rio Preto were obtained.

\section{RESULTS}

This study examined 106 nevoid lesions after removal dermoscopically and histopathologically in 48 patients, 37 women and 11 men, aged between 14 and 72 years to evaluate the sensitivity and specificity of the dermoscopy method in the diagnosis of pigmented lesions.

Out of the 106 lesions dermoscopically analyzed, 67 had suspected atypia. After surgical removal, the atypia was confirmed histopathologically in 14 lesions, but other dermoscopic suspicious were not confirmed. According to the histopathological diagnosis, the lesions with false-positive results (53 lesions) were classified as compound nevi (30 lesions), junctional nevus (15 lesions), intradermal nevus (04 lesions), pigmented seborrheic keratosis (03 lesions) and blue nevus (01 lesion) (Figure 1).

Among the assessed lesions, 39 were removed without atypia according to dermoscopy, and 38 received the same histopathological diagnosis (no atypia); only 01 lesion was diagnosed with atypical nevus. Therefore, we observed only one lesion whose atypia was not diagnosed by dermoscopy; this represented the only case of false negative in the sample (Chart 1). The dermoscopic classification of this lesion was compound nevi, however, it was histopathologically classified as dysplastic compound nevi with mild cellular atypia.

Thus, the sensitivity of dermatoscopy assessed by the Method of Pattern Analysis was 93\% (ci 95\%: 68 to $99,8 \%$ ), while specificity was $42 \%$ (ci $95 \%$ : 32 to $53 \%$ ) (Graphs 1 and 2). The likelihood of positive ratio was 1.6 (ci 95\%: 1 to 2) and the likelihood of negative ratio was 0.2 (ci 95\%: 0.004 to 0.99 ).

Analyzing the predictive value of the test we could observe that out of the 67 nevi diagnosed as atypical, only 14 actually were; demonstrating that dermoscopy had a low positive predictive value, that is, only $21 \%$ (ci $95 \%$ : 12 to $33 \%$ ) of atypical nevi,

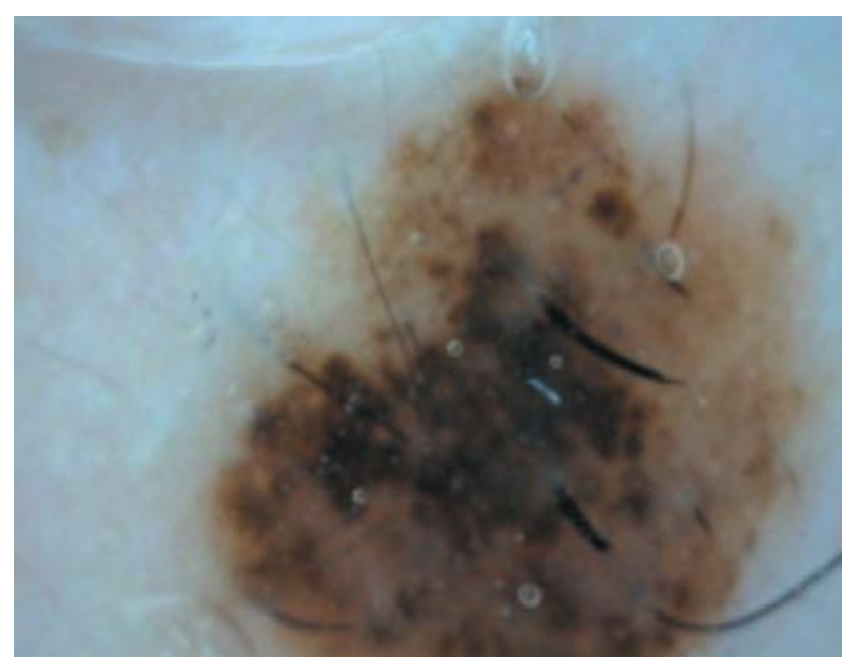

FIGURE 1: One of the 53 false positive lesions dermoscopically diagnosed as atypical, but that received the histopathologic diagnosis of composed melanocytic nevi without atypia 
CHART 1: Ratio of true positive, true negative, false positive and false negative diagnoses in the dermatoscopic diagnosis of atypical nevi in relation to the histopathological diagnosis (gold standard)

\begin{tabular}{|c|c|c|c|c|}
\hline & & Histopathology & Histopathology & Histopathology \\
\hline & & Positive & Negative & Total \\
\hline Dermoscopy & Positeve & True Positive: 14 & False Positive: 53 & 67 \\
\hline Dermoscopy & Negative & False Negative: 1 & True Negative: 38 & 39 \\
\hline Dermoscopy & Total & 15 & 91 & 106 \\
\hline
\end{tabular}
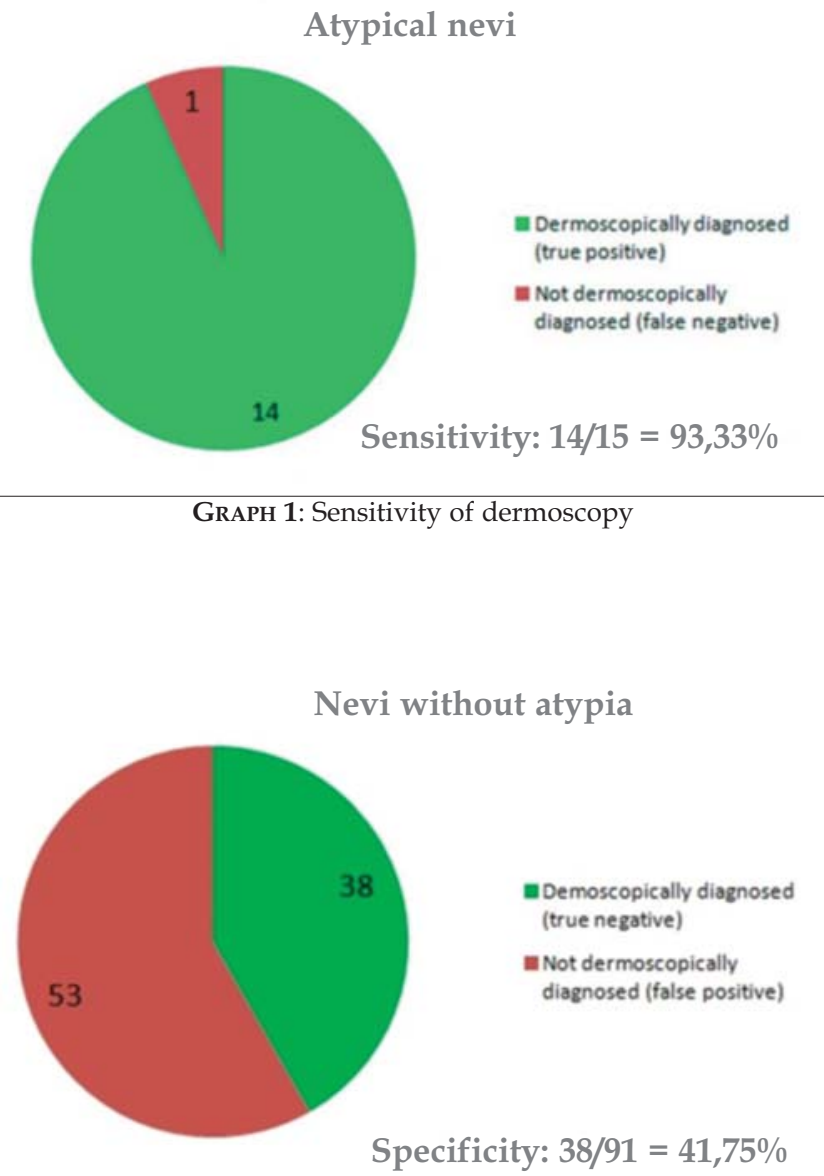

GRAPH 2: Specificity of dermoscopy

according to dermatoscopic diagnosis, had the same histopathological diagnosis. Regarding the negative predictive value, dermoscopy had a high value, $97 \%$ (ci $95 \%$ : 87 to $99.9 \%$ ), since 39 nevi were without atypia by histopathology; 38 were diagnosed by dermatoscopy and only one was not.

\section{DISCUSSION}

Clinical diagnosis of pigmented lesions is of great importance to differentiate between benign, atypical and malignant lesions. Because these lesions are not often diagnosed by their clinical features, additional criteria, such as dermoscopy, are necessary for a more accurate clinical diagnosis of the lesions..$^{15,16}$

Since dermoscopy has demonstrated high sensitivity in this study, $93 \%$ of atypical nevi could be diagnosed, therefore allowing accurate diagnosis in most cases of atypia and preventing them from going unnoticed. The low specificity $(42 \%)$ reveals high rates of false positives, providing a low positive predictive value, as only $1 / 5$ of atypical nevi are dermoscopically diagnosed; they are also histopathologically diagnosed. Still, with a high negative predictive value, the test ensures certainty in almost all the negative dermoscopic diagnoses (97\%) allowing the assurance of not overlooking an atypical case when it was not dermoscopically diagnosed.

Thus, dermoscopy shows great efficacy in diagnosing atypical nevi, reaching its goal in the screening of malignant lesions. On the other hand, it has low efficiency when diagnosing nevi without atypia, as it finds a large number of false positives (53 nevi), corresponding to $58 \%$ of nevi without atypia.

Some authors reported that dermoscopy increases the diagnostic accuracy of clinically equivocal melanocytic lesions, which allows the distinction between benign and malignant patterns of growth. $6,27,28$ These data show that dermoscopy is a sensitive method for the diagnosis of pigmented lesions; these findinds were confirmed in our study. Procianoy, 2009, also demonstrated the sensitivity of dermoscopy through the Method of Pattern Analysis, finding the value of $91.7 \%$, while specificity of the method was $41.7 \%$

Given the high level of sensitivity found in this study, the dermatoscopic method has fundamental importance for the screening of atypical lesions, being effective to detect the great majority of them, promoting early diagnosis and better prognosis for patients with cutaneous melanoma.

\section{CONCLUSIONS}

In view of the purpose of this study, we concluded that dermoscopy technique presented sensi- 
tivity of $93 \%$ and specificity of $42 \%$ in the diagnosis of pigmented skin lesions when compared to the histopathology method, considered the gold standard for this purpose.

Although dermoscopy is not as specific as histopathology and does not replace clinical diagno- sis, it can be considered an effective methodology to identify pigmented lesions with atypia since it is sensitive, simple, practical, non-invasive and affordable. These data become even more relevant in view of the high incidence of cutaneous melanoma, early diagnosis being essential for patient healing.

\title{
REFERENCES
}

1. Instituto Nacional de Câncer (Brasil). Prevenção e controle do câncer: normas e recomendações do INCA. Rev Bras Cancerol. 2002;48:317-32.

2. Gandini S, Sera F, Cattaruzza MS, Pasquini P, Zanetti R, Masini C, et al. Meta-analysis of risk factors for cutaneous melanoma: III. Family history, actinic damage and phenotypic factors. Eur J Cancer. 2005;41:2040-59.

3. Harmful effects of ultraviolet radiation. Council on Scientific Affairs. JAMA. 1989;262:380-4.

4. Bonfá R, Bonamingo RR, Bonfá R, Duro KM, Furian RD, Zelmanowicz AM. Early diagnosis of cutaneous melanoma: an observation in southern Brazil. An Bras Dermatol. 2011;86:215-21.

5. Grinblat M. Prevenção do Câncer de Pele [tese]. São Paulo (SP): Hospital Israelita Albert Einstein; 2003.

6. Miracco C, Palummo N, Lavergne D, Nyongo A, Tosi P, de Villiers EM. Malignant melanomas: search for human papillomaviruses. Arch Dermatol. 2001;137:826-7.

7. Pehamberger $H$, Steiner A, Wolff K. In vivo epiluminescence microscopy of pigmented skin lesions. I. Pattern analysis of pigmentes skin lesions. J Am Acad Dermatol. 1987; $17: 571-83$.

8. Friedman RJ, Farber MJ, Warycha MA, Papathasis N, Miller MK, Heilman ER. The "dysplastic" nevus. Clin Dermatol. 2009;27:103-15.

9. Holly EA, Kelly JW, Shpall SN, Chiu SH. Number of melanocytic nevi as a major risk for malignant melanoma. J Am Acad Dermatol. 1987;17:459-68.

10. Tucker MA, Halpern A, Holly EA, Hartge P, Elder DE, Sagebiel RW, et al. Clinically recognized dysplastic nevi: a central risk factor for cutaneous melanoma. JAMA. 1997;227:1439-44.

11. Shors AR, Kim S, White E, Argenyi Z, Barnhill RL, Duray P, et al. Dysplastic naevi with moderate to severe histological dysplasia: a risk factor for melanoma. Br J Dermatol. 2006;155:988-93.

12. Rezze GG, Leon A, Duprat J. Nevo displásico (nevo atípico). An Bras Dermatol. 2010;85:863-71.

13. Elder DE, Goldman LI, Goldman SC, Greene MH, Clark WH Jr. Dysplastic nevus syndrome: a phenotypic association of sporadic cutaneous melanoma. Cancer. 1980;46:1787-94

14. Tripp JM, Kopf AW, Marghoob AA, Bart RS. Management of dysplastic nevi: a survey of fellows of the American Academy of dermatology. J Am Acad Dermatol. 2002;46:674-82.

15. Dal Pozzo V, Benelli C, Roscetti E. The seven features for melanoma: a new dermoscopic algorithm for the diagnosis of malignant melanoma. Eur $\mathrm{J}$ Dermatol. 1999;9:303-8.

16. Soyer HP, Argenziano G, Ruocco V, Chimenti S. Dermoscopy of pigmented skin lesions (Part II). Eur J Dermatol. 2001;11:483-98.

17. Soyer HP, Smolle J, Hodl S, Pachernegg H, Kerl H. Surface microscopy: a new approach to the diagnosis of cutaneous pigmented tumors. Am J Dermatopathol. 1989;11:1-10.

18. Soyer HP, Argenziano G, Talamini R, Chimenti S. Is dermoscopy useful for the diagnosis of melanoma? Arch Dermatol. 2001;137:1361-3.

19. Argenziano $\mathrm{G}$, Soyer HP. Dermoscopy of pigmented skin lesions - a valuable tool for early diagnosis of melanoma. Lancet Oncol. 2001;2:443-9.

20. Acosta AE, Fierro E, Velásquez VE, Rueda X. Melanoma: patogénesis, clínica e histopatología. Rev Asoc Col Dermatol. 2009;17:87-108.

21. Nachbar F, Stolz W, Merkle T, Cognetta AB, Vogt T, Landthaler M, et al. The ABCD rule of dermatoscopy: high prospective value in the diagnosis of doubtful melanocytic skin lesions. J Am Acad Dermatol. 1994;30:551-9.

22. Steiner $A$, Pehamberger $H$, Wolf $K$. In vivo epiluminescence microscopy of pigmented skin lesions, II: diagnosis of small pigments skin lesions and early detection of malignant melanoma. J Am Acad Dermatol. 1987;17:584-91.

23. Lorentzen H, Weismann K, Petersen CS, Larsen FG, Secher L, Skødt V. Clinical and dermatoscopic diagnosis of malignant melanoma assessed by expert and non expert groups. Acta Derm Venereol. 1999;79:301-4.

24. Binder M, Schwarz M, Winkler A, Steiner A, Kaider A, Wolff K, et al. Epiluminescence microscopy, a useful tool for the diagnosis of pigmented skin lesions for formally trained dermatologists. Arch Dermatol. 1995;131:286-91.

25. Procianoy PDC. Correlação entre o diagnóstico clínico, dermatoscópico e histológico de nevos atípicos [dissertação]. Porto Alegre (RS): Universidade Federal do Rio Grande do Sul; 2009.

26. Mireles-Rocha H. Dermatoscopia. Rev Cent Dermatol Pascua. 1996;5:13-7.

27. Pehamberger $H$, Binder M, Steiner A, Wolff K. In vivo epiluminescence microscopy: improvement of early diagnosis of melanoma. J Invest Dermatol. 1993;100:356S-62S.

28. Salopek TG, Kopf AW, Stefanato CM, Vossaert K, Silverman M, Yadav S. Differentiation of atypical moles (dysplastic nevi) from early melanomas by dermatoscopy. Dermatol Clin. 2001;19:337-45.

29. Rezze GG, Sá BCS, Neves RI. Dermatoscopia: 0 método de análise de padrões. An Bras Dermatol. 2006;81:261-8.

\author{
MAILING ADDRESS: \\ Lívia Arroyo Trídico \\ Rua Antonio Carlos Montanhês, 320 \\ Mansur Daud \\ 15070-550 - São José do Rio Preto - SP \\ Brazil \\ E-mail: latridico@terra.com.br
}

How to cite this article: Antonio JR, Soubhia RMC, D'Avila SCGP, Caldas AC, Trídico LA, Alves FT. Correlation between dermoscopic and histopathological diagnoses of atypical nevi in a dermatology outpatient clinic of the Medical School of São José do Rio Preto, SP. An Bras Dermatol. 2013;88(2):199-203. 